American Journal of Applied Sciences 8 (7): 662-674, 2011

ISSN 1546-9239

(C) 2011 Science Publications

\title{
Performance Evaluation of an Oxidation Ditch System with a Disc Aerator
}

\author{
Abdel Ghaly and Ashley Thistle \\ Department of Process Engineering and Applied Science \\ Dalhousie University, Halifax, Nova Scotia, Canada
}

\begin{abstract}
Problem statement: The oxidation ditch system has been used to treat various types of wastewaters. Several types of aerators are used to supply the treatment process with oxygen. Among these devices, the disc aerator has certain advantages regarding foam generation over the brush and paddle type rotors, but the main disadvantages of this aerator is the limited oxygenation capacity. The main objectives of this study were to study the effects of various design parameters and system operation parameters on the oxygenation capacity of the system. Approach: A bench scale oxidation ditch system equipped with a disc aerator was used to gain better understanding of the phenomena of oxygen transfer and to study the effects of hole diameter, number of holes per disc, disc thickness, disc speed, immersion depth and number of discs on the oxygenation capacity of the system. The unsteady state method with sulphite oxidation was used to deoxygenate the water. The test involved chemical removal of dissolved oxygen from water followed by oxygenation. The power consumed was measured, the oxygen transfer coefficient was determined and both the oxygenation capacity and oxygenation efficiency were calculated. Results: The oxygen transfer coefficient was affected by the immersion depth, hole diameter, disc speed, disc thickness and number of discs, with the disc speed having the greatest effect. The results showed that three physical processes simultaneously contributed to oxygen transfer by the disc aerator: bubble aeration, eddy aeration and surface aeration. Conclusion: The use of sodium sulphite with cobalt chloride for deoxygenation of the water via the oxidation ditch was effective and the results were very consistent and repeatable. The aerator disc of $2.55 \mathrm{~cm}$ thickness, $1.92 \mathrm{~cm}$ diameter and 48 holes was found to achieve the highest oxygenation capacity. The system is anticipated to provide a broad range of oxygen transfer rates under actual conditions (23-164 $\mathrm{mgO}_{2} / \mathrm{L}-\mathrm{h}$ ) to meet varying process demands encountered in aerobic treatment systems.
\end{abstract}

Key words: Oxidation ditch, aeration, deoxygenate, oxygen transfer, oxygenation capacity, disc aeration, coefficient, biological treatment, mass transfer mechanisms, diffusion coefficient, liquid phase, sodium sulphite

\section{INTRODUCTION}

Wastewaters have been successfully treated using aerobic biological systems. (Pell and Worman, 2008; LaPara and Alleman, 1998; Groves et al., 1992; Fenlon and Mills, 1980). The main functions of any aeration device are to: (a) supply a sufficient quantity of oxygen to the liquid medium to maintain aerobic conditions, (b) circulate the liquid to keep solids in suspension and avoid settling, (c) distribute the oxygenated liquid throughout the liquid body to avoid anaerobic zones and (d) keep good contact between the microbial cells, nutrients and dissolved oxygen to ensure efficient biodegradation of the organic matter (Gresch et al., 2010). From the viewpoint of the operators, the aeration process should be accomplished at the least cost per kilogram of waste treated.

The oxidation ditch system has been successfully used for wastewater treatment (Liu et al., 2009; Xie et al., 2006; Xia and Liu, 2003). The ditch essentially consists of a closed loop, open channel in which liquid circulation and oxygen input are maintained by a mechanical device. The disc aerator described by $(\mathrm{Wu}$, 1995; Gomolka and Gomolka, 1991; Ghaly and Kok, 1986) is an alternative to the brush and paddle wheel rotors which are traditionally used in oxidation ditches (Moulick et al., 2002; Jones et al., 1971). It has certain advantages with regard to foam generation but the oxygenation capacity of an individual disc was reported to be limited and the use of a number of discs on the rotating shaft was suggested in order to allow for a

Corresponding Author: Abdel Ghaly, Department of Process Engineering and Applied Science, Dalhousie University, Halifax, Nova Scotia, Canada Tel: (902) 494-6015 
wider range of oxygenation capacities (Drews et al., 1972). From the point of energy consumption, it would be more fruitful to try to improve the oxygenation capacity of a single disc aerator rather than merely use large numbers of discs. This can be achieved by better understanding of the mechanisms of oxygen transfer by the disc aerator and investigating the effects of various disc design parameters and system operation parameters on the oxygenation capacity of the disc.

The main objectives of this study were to: (a) investigate the effects of various disc design parameters (hole diameter, disc thickness and number of holes per disc) and system operational parameters (rotational speed, immersion depth and number of discs) on the oxygen transfer coefficient, (b) calculate the oxygenation capacity of the system and (c) understand the physical phenomena of oxygen transfer in the oxidation ditch.

Oxygen transfer: Aeration is used to transfer oxygen to a biological treatment process. It is a gas-liquid mass-transfer process in which interphase diffusion occurs when a driving force is created by departure from equilibrium (Gresch et al., 2010; Pawar et al., 2009). The driving force is a difference in activity between the two phases (gas and liquid) and is usually expressed in terms of a concentration or partial pressure difference (Pawar et al., 2009). However, the various mass transfer mechanisms that have been reported in the literature are based on Fick's Law of diffusion:

$$
\mathrm{N}=\mathrm{DA}\left(\frac{\mathrm{dc}}{\mathrm{dy}}\right)
$$

Where:

$\mathrm{N}=$ The time rate of mass transfer $\left(\mathrm{gs}^{-1}\right)$

$\mathrm{D}=$ The diffusion coefficient $\left(\mathrm{cm}^{2} \mathrm{~s}^{-1}\right)$

$\mathrm{A}=$ The cross-sectional area through which diffusion occurs $\left(\mathrm{cm}^{2}\right)$

$\frac{\mathrm{dc}}{\mathrm{dy}}=$ The concentration gradient perpendicular to the cross-sectional area $\left(\mathrm{gcm}^{-4}\right)$

Two mechanisms have been suggested for explaining the mass transfer between the gas-liquid phases: the two film theory and the penetration theory. Assuming equilibrium at the gas-liquid interface, the mass transfer can be expressed as follows:

$$
N=D_{G} A\left(\frac{d c}{d y}\right)=D_{L} A\left(\frac{d c}{d y}\right)=D_{E}\left(\frac{d c}{d y}\right)
$$

Where:

$\mathrm{D}_{\mathrm{G}}=$ The diffusivity coefficient through the gas film $\left(\mathrm{cm}^{2} \mathrm{~s}^{-1}\right)$

$\mathrm{D}_{\mathrm{L}}=$ The diffusivity coefficient through the liquid film $\left(\mathrm{cm}^{2} \mathrm{~s}^{-1}\right)$

$D_{E}=$ The eddy coefficient of diffusion from the gas to liquid film $\left(\mathrm{cm}^{-4} \mathrm{~s}^{-1}\right)$

$\frac{\mathrm{dc}}{\mathrm{dy}}=$ The partial pressure gradient perpendicular to the cross-sectional area $\left(\mathrm{gcm}^{-4}\right)$

The two film theory: The interface between two phases is modeled as a set of two stagnant films, one on the gas side and the other at the liquid side. Mass transfer then occurs by sequential molecular diffusion through the two films as shown in Fig. 1 (Haut and Halloin, 2003). With this concept, equation 2 can be written in terms of a gas and liquid films as follows:

$\mathrm{N}=\mathrm{K}_{\mathrm{L}} \mathrm{A}\left(\mathrm{C}_{\mathrm{S}}-\mathrm{C}_{\mathrm{L}}\right)=\mathrm{K}_{\mathrm{G}} \mathrm{A}\left(\mathrm{P}_{\mathrm{t}}-\mathrm{P}_{\mathrm{G}}\right)$

Where:

$\mathrm{N}=$ The time rate of mass transfer $\left(\mathrm{gs}^{-1}\right)$

$\mathrm{K}_{\mathrm{L}}=$ The liquid film rate constant, defined as $\mathrm{D}_{\mathrm{L}} / \mathrm{Y}_{\mathrm{L}}\left(\mathrm{cms}^{-1}\right)$

$K_{G}=$ The gas film rate constant, defined as $D_{S} / Y_{G}$ $\left(\mathrm{gPa}^{-1} \mathrm{~cm}^{-2} \mathrm{~s}^{-1}\right)$

$\mathrm{C}=$ The concentration of solute in the liquid at the interface $\left(\mathrm{gcm}^{-3}\right)$

$\mathrm{C}_{\mathrm{L}}=$ The concentration of solute in the liquid $\left(\mathrm{gcm}^{-3}\right)$

$P_{G}=$ The partial pressure in the gas phase $\left(\mathrm{gcm}^{-3}\right)$

$\mathrm{P}=$ The partial pressure at the interface $\left(\mathrm{gcm}^{-3}\right)$

$\mathrm{A}=$ The cross-sectional area through which diffusion occurs $\left(\mathrm{cm}^{2}\right)$

For a sparingly soluble gas such as oxygen, the liquid film resistance controls the rate of mass transfer. The diffusion is assumed to occur only in a direction perpendicular to the interface and the two films are thought of as persisting regardless of how much turbulence is present in the gas and liquid (Echenfelder, 1959; Wang, 1995).

The penetration theory: It is postulated that the contact between phases occurs in a series of intermittent steps and the mass transfer rate is a function of the contact time. Elements of fluid move periodically from the turbulent core to the phase boundary, rest there a short time and are then replaced by other elements from the bulk liquid (Fig. 2). 
Am. J. Applied Sci., 8 (7): 662-674, 2011
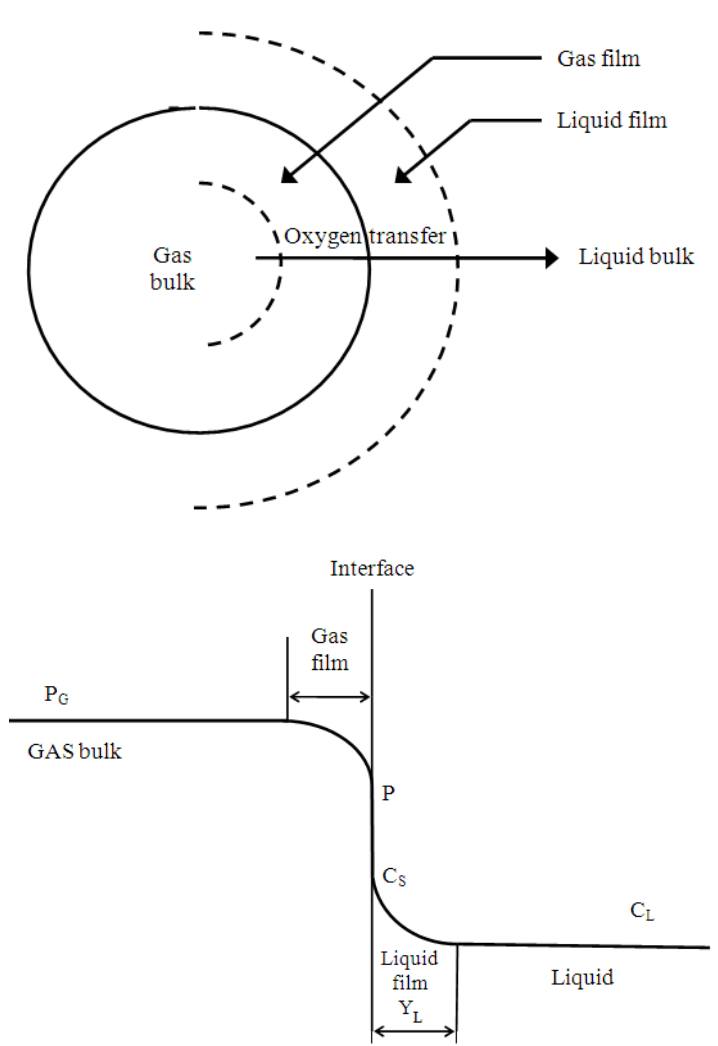

Fig. 1: Schematic representation of gradients in the stagnant gas and liquid films during interphase mass transfer

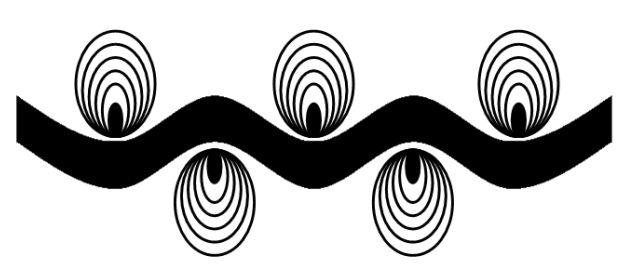

Fig. 2: Suggested mechanism of mass transfer across an interface via eddy surface renewal

The mass transfer takes place exclusively by molecular diffusion during the period of contact in a direction perpendicular to the interface with regular frequency, i.e., the time that each element of fluid remains in contact with the phase boundary is constant (Nedeltchev et al., 2007). The rate of oxygen transfer $\left(\mathrm{K}_{\mathrm{L}}\right)$ was defined as follows (Miller, 1964; McCabe et al., 2004; Nedeltchev et al., 2007):

$$
\mathrm{K}_{\mathrm{L}}=2 \sqrt{\frac{\mathrm{D}_{\mathrm{L}}}{\tau_{\mathrm{e}}}}
$$

where, $t_{\mathrm{e}}$ is the time of exposure of the eddy to air (s).

Dankwarts (1951) discovered that the displacement of fluid elements from a phase boundary is completely random and there is no dependence on the time of contact. He assumed the rate of displacement of liquid elements to be constant over the whole contact time and defined $\mathrm{K}_{\mathrm{L}}$ as follows:

$$
\mathrm{K}_{\mathrm{L}}=\sqrt{\mathrm{D}_{\mathrm{L}} \cdot \mathrm{r}}
$$

where, $r$ is the rate of surface renewal $\left(\mathrm{sec}^{-1}\right)$.

However, neither the time of exposure of the eddy to the gas phase $\left(t_{e}\right)$ nor the rate of surface renewal (r) can be easily calculated with accuracy (Ghaly and Edwards, 2011).

Over-all volumetric mass transfer coefficient: In most types of gas transfer systems, it is not possible to measure the interfacial area of contact between gas and liquid. For this reason, use is made of the over-all volumetric mass transfer coefficient in which are combined the interfacial area per unit volume and the mass transfer coefficient (Ghaini et al., 2010). At steady state, when the oxygen concentration in the liquid phase remains relatively constant, the transfer rate is calculated by means of the following equation:

$$
\mathrm{N}=\mathrm{K}_{\mathrm{L}} \mathrm{aV}\left(\mathrm{C}_{\mathrm{S}}-\mathrm{C}_{\mathrm{L}}\right)
$$

Where:

$\mathrm{V}=$ The volume of the system $\left(\mathrm{cm}^{3}\right)$

$\mathrm{K}_{\mathrm{L}} \mathrm{a}=$ Tthe overall volumetric mass transfer coefficient based on the liquid phase $\left(\mathrm{sec}^{-1}\right)$

The objective of aeration and agitation management in a wastewater treatment system is to achieve a value of $\mathrm{K}_{\mathrm{L}} \mathrm{a}$ such that the oxygen supply meets the oxygen demand of the microorganisms at a value of $\mathrm{C}_{\mathrm{L}}$ sufficient for the microorganisms to exist.

\section{MATERIALS AND METHODS}

Experimental apparatus: A bench scale oxidation ditch system (Fig. 3) equipped with a disc aerator was set up to gain an understanding of the phenomenon of oxygen transfer and to study the effects of the disc design parameters and system operation parameters on the rate of oxygen transfer in deionized water. The equipment included the oxidation ditch and hood, aerator discs and rotating shaft, a motor and a speed controller. 
Am. J. Applied Sci., 8 (7): 662-674, 2011

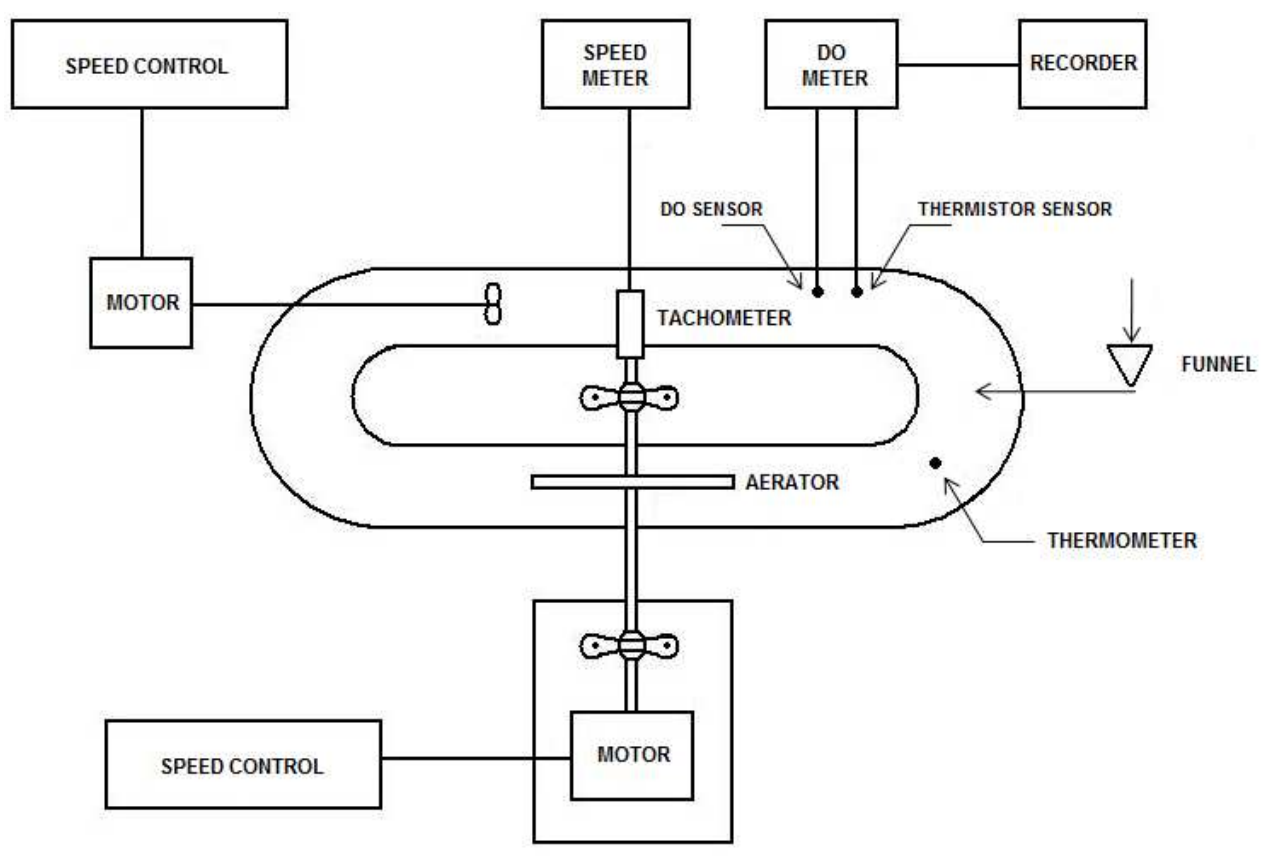

Fig. 3: Schematic diagram of the oxidation ditch and associated apparatus

A race track type oxidation ditch was constructed of acrylic plastic (Fig. 4). The thickness and height of the ditch walls are 0.4 and $16.0 \mathrm{~cm}$, respectively. The walls of the ditch were glued onto a $76 \times 38 \mathrm{~cm}$ acrylic plate of $0.6 \mathrm{~cm}$ thickness.

The inner and outer diameters of the circular part of the ditch were 15 and $30 \mathrm{~cm}$, respectively. The length of the ditch side was $31.5 \mathrm{~cm}$. This length was used to obtain a ditch area of $1000 \mathrm{~cm}^{2}$ and a volume of $16000 \mathrm{~cm}^{3}$. The aerator was covered with an acrylic hood to avoid loss of the ditch contents by splashing.

The aerator discs were fabricated of acrylic plastic. The diameter of the discs was $29 \mathrm{~cm}$. Holes were drilled in the outer $7 \mathrm{~cm}$, parallel to the disc axis. The independent variables considered in the design of the discs were: disc thickness, hole diameter and number of holes. Five levels of disc thickness $(0.32,0.64,1.28$, 1.92 and $2.55 \mathrm{~cm}$ ) and five levels of hole diameter $(0.00,0.32,0.64,1.28$ and 1.29$)$ were studied. A total of twenty five discs were fabricated. The number of holes drilled in the discs was such that all discs had the same perforated area $\left(123 \mathrm{~cm}^{2}\right.$ out of $660 \mathrm{~cm}^{2}$ or $\left.19 \%\right)$. This resulted in 1536, 384, 96 and 43 holes per disc for the discs having $0.32,0.64,1.28$ and $1.92 \mathrm{~cm}$ hole diameters, respectively.

The disc was mounted on a rotating shaft so that it was partially submerged in the ditch contents. The disc shaft was driven by an adjustable speed (0-500 rpm) electric motor (Steadi-Speed Stirrer No. 14-498A,
Fisher Scientific, Montreal, Quebec, Canada). The motor shaft was attached to the disc shaft through a chuck assembly. The disc immersion depth was adjusted by lowering or raising both the drive and disc shafts to the required height using two pieces of Plexiglas of the same thickness $(2.5$ and $5.0 \mathrm{~cm})$ under the bearings. A generator tachometer (Servo-Tek Model ST-9540-20, Fisher Scientific, Montreal, Quebec, Canada) was connected to the disc shaft by means of a Tygon tube to measure the speed of rotation.

A general purpose filtering funnel (Kimble 28950 No 10-322E, Fisher Scientific, Montreal, Quebec, Canada) was used to gradually add sodium sulphite and cobalt chloride solutions to the ditch. The funnel was connected to the ditch by a Tygon tube. An impeller of $31 \mathrm{~cm}$ length and $4.4 \mathrm{~cm}$ propeller diameter was connected to a stirring apparatus (Dyna-Mix Model 43, Fisher Scientific, Montreal, Quebec, Canada) with the propeller at the mid-depth of the ditch and used to circulate and mix the ditch contents during the deoxygenation process. Dissolved oxygen was measured by a polarographic electrode (Beckman $39553 \mathrm{O}_{2}$ Sensor) connected to a dissolved oxygen meter (Beckman Fieldlab Oxygen Analyzer Model 1008, Fisher Scientific, Montreal, Quebec, Canada). The signal from the dissolved oxygen meter was recorded continuously on a servo recorder (Health Model Eu-20B, Fisher Scientific, Montreal, Quebec, Canada). Liquid temperature was measured by a 
thermistor sensor (Beckman Model 39590, Fisher Scientific, Montreal, Quebec, Canada) and air temperature was measured by a mercury thermometer. The barometric pressure was measured by a mercury barometer (Fisher 2-383, Fisher Scientific, Montreal, Quebec, Canada). Power requirements were measured by a single element wattmeter (Crompton Parkinson No. 1672070, Tyco Electronics, Witham, Essex, UK). A Locam $16 \mathrm{~mm}$ High Speed Motion Picture Camera (500 frames per second) was used to film the movement of bubbles and eddies during the aeration process.

Experimental design: Three independent disc design variables (disc thickness, hole diameter and number of holes) and three operational variables (disc immersion depth, disc rotational speed and number of discs) were considered for manipulation to maximize the oxygen transfer capacity of the system. However, a complete factorial experiment including all six factors was considered impractical. Therefore, five sets of experiments were carried out.

In the first set of experiments, the oxygen transfer coefficient $\left(\mathrm{K}_{\mathrm{L}} \mathrm{a}\right)$ was determined at three immersion depths $(2.5,5.0$ and $7.5 \mathrm{~cm})$ and five disc speeds $(50$, $100,150,200$ and $250 \mathrm{rpm})$ using the disc of $0.64 \mathrm{~cm}$ thickness having 48 holes of $1.28 \mathrm{~cm}$ diameter.

In the second set of experiments, the effects of disc speed and hole diameter on $\mathrm{K}_{\mathrm{L}} \mathrm{a}$ were studied. An immersion depth of $7.5 \mathrm{~cm}$ and a disc thickness of 0.64 $\mathrm{cm}$ were maintained during all experiments. These values for immersion depth and disc thickness were chosen randomly. Five hole diameters $(0.00,0.32,0.64$, $1.28,1.92 \mathrm{~cm})$ and five disc speeds $(50,100,150,200$ and $250 \mathrm{rpm}$ ) were used. All of the discs have the same perforated area.

In the third set of experiments, the effects of disc speed and disc thickness on $\mathrm{K}_{\mathrm{L}} \mathrm{a}$ were studied. Four discs of $0.64,1.28,1.92$ and $2.55 \mathrm{~cm}$ thickness (all having equal perforated volumes of $85 \mathrm{~cm}^{3}$ ) and five disc speeds (50, 100, 150, 200 and $250 \mathrm{rpm})$ were used. An immersion depth of $7.5 \mathrm{~cm}$ was maintained throughout the experiments.

In the fourth set of experiments, an attempt was made to study the effects of using more than one aerator disc on the rotating shaft on $\mathrm{K}_{\mathrm{L}} \mathrm{a}$. Because of the limited width of the ditch $(7.5 \mathrm{~cm})$, it was only feasible to install a maximum of two discs spaced at $2.5 \mathrm{~cm}$ on the rotating shaft. This was done for two disc thicknesses $(0.32$ and $0.64 \mathrm{~cm})$. An immersion depth of $7.5 \mathrm{~cm}$ was maintained during the experiments. $\mathrm{K}_{\mathrm{L}} \mathrm{a}$ values were obtained for these two discs at five disc speeds (50, $100,150,200$ and $250 \mathrm{rpm}$ ) and the values were compared with those obtained when using single discs of the same thickness and double thickness.

In the fifth set of experiments, the oxygenation capacity of the optimum disc was determined at various speeds. The values of $\mathrm{K}_{\mathrm{L}}$ a were used to calculate the oxygenation capacity. The Oxygenation Capacity (OC) was defined in this study as the weight of oxygen per unit time $\left(\mathrm{gO}_{2} / \mathrm{h}\right)$ that could be introduced into a completely deoxygenated body of water at $20^{\circ} \mathrm{C}$ and $101.3 \mathrm{kPa}$ and it can be described by the following equation:

$\mathrm{OC}=\mathrm{K}_{\mathrm{L}} \mathrm{a} \mathrm{C}_{\mathrm{S}} \mathrm{V}$

The oxygenation efficiency was defined as the weight of oxygen that can be introduced into a completely deoxygenated body of water at $20^{\circ} \mathrm{C}$ and $101.3 \mathrm{kPa}$ per unit energy consumed $\left(\mathrm{gO}_{2 /} \mathrm{MJ}\right)$. The power requirement of the system operating with the disc of $2.55 \mathrm{~cm}$ thickness, having 48 holes of $1.92 \mathrm{~cm}$ diameter and an immersion depth of $7.5 \mathrm{~cm}$, was measured at 50, 100, 150, 200 and $250 \mathrm{rpm}$. The power input to the motor drive was measured with and without liquid in the ditch. The net power input was taken as the difference between these two measured power values.

Experimental procedure: A number of experiments were performed to determine the values of the oxygen transfer coefficient $\left(\mathrm{K}_{\mathrm{L}} \mathrm{a}\right)$ in the oxidation ditch under various conditions. During each experimental run, the ditch contents were aerated, deoxygenated and then reaerated. The unsteady state method with sulphite oxidation described by Ghaly and Kok (1988) was used. The test involves the chemical removal of dissolved oxygen from water by oxidation of sodium sulphite (with cobalt added as a catalyst). The chemical reaction is as follows:

$\mathrm{Na}_{2} \mathrm{SO}_{3}+0.5 \mathrm{O}_{2} \underline{\mathrm{C}_{0} \mathrm{Cl}_{2}} \mathrm{Na}_{2} \mathrm{SO}_{4}$

Theoretically, $7.9 \mathrm{mg} \mathrm{\textrm {L } ^ { - 1 }}$ sodium sulphite is needed for each $\mathrm{mg} \mathrm{L}^{-1}$ of DO. However, because it is necessary to mix the sodium sulphite throughout the aeration tank before the test starts, oxidation of some sulphite occurs during the mixing period. Therefore, the addition of approximately 1.5-2.0 times of the theoretical quantity of sodium sulphite has been suggested by Ghaly and Kok (1988) as being necessary to deoxygenate the basin.

Initially, the ditch was cleaned thoroughly with tap water and then flushed several times with deionized water before each run. Eleven litres of deionized water were then added to the ditch. The dissolved oxygen meter, recorder and aerator were started simultaneously and the liquid and air temperatures and barometric pressure were recorded. 


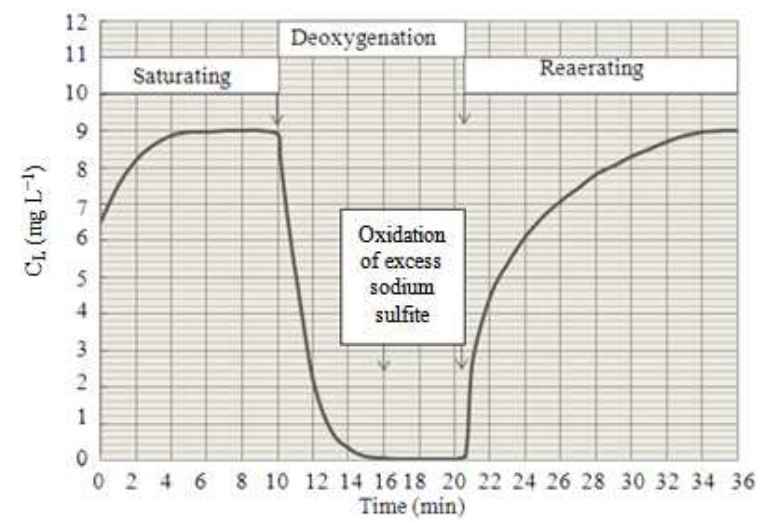

Fig. 4:The oxygen concentration curve obtained during a typical experimental run

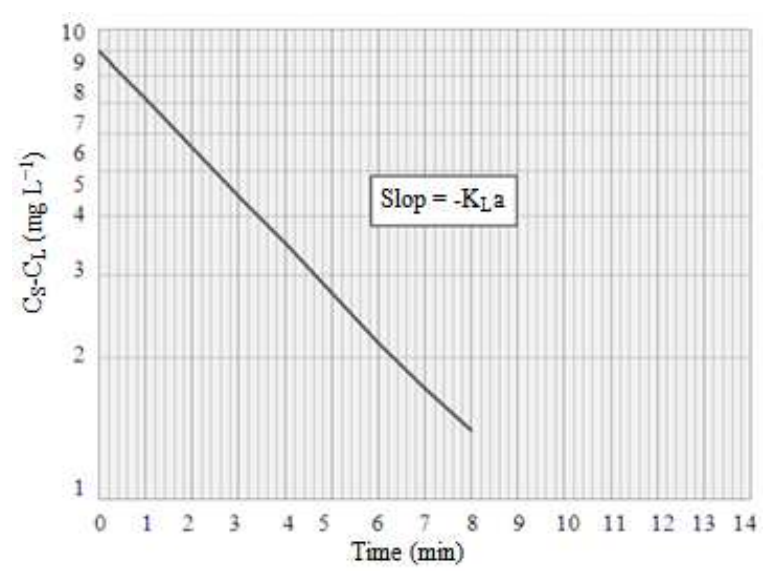

Fig. 5: Determination of $\mathrm{K}_{\mathrm{L}} \mathrm{a}$

When the oxygen saturation concentration $\left(\mathrm{C}_{\mathrm{S}}\right)$ was reached (the oxygen concentration curve became flat), the aerator motor was switched off and $13.8 \mathrm{~mL}$ of $0.10 \mathrm{M} \mathrm{Na}_{2} \mathrm{SO}_{3}$ solution (173.8 $\mathrm{mg}$ of sodium sulphite) and $1.6 \mathrm{ml}$ of $0.01 \quad \mathrm{M} \mathrm{CoCl}_{2} \cdot 6 \mathrm{H}_{2} \mathrm{O}$ solution (2.2 mg of cobalt chloride) were added. These solutions were distributed throughout the oxidation ditch by the impeller. When the water was completely deoxygenated, the impeller was shut off and the disc aerator was started. The dissolved oxygen concentration $\left(\mathrm{C}_{\mathrm{L}}\right)$ then increased until it reached the saturation concentration $\left(\mathrm{C}_{S}\right)$. During a typical experiment, $C_{L}$ remained at zero until the excess sodium sulphite had been oxidized, rose rapidly at the beginning and then slowly approached its saturation value again (Fig. 4). The overall volumetric oxygen transfer coefficient was then calculated according to the following equation:

$$
\frac{\mathrm{dc}}{\mathrm{dt}}=\mathrm{K}_{\mathrm{L}} \mathrm{a}\left(\mathrm{C}_{\mathrm{S}}-\mathrm{C}_{\mathrm{L}}\right)
$$

At a time $\mathrm{t}=0, \mathrm{C}_{\mathrm{L}}=0$ and the above equation on investigation yields the following equation:

$\mathrm{C}_{\mathrm{L}}=\mathrm{C}_{\mathrm{S}} \mathrm{e}^{-\mathrm{K}_{\mathrm{L}} \mathrm{at}}$

The values of $\left(\mathrm{C}_{\mathrm{S}}-\mathrm{C}_{\mathrm{L}}\right)$ were plotted on semilogarithmic study against time resulting in a straight line with a slope equal to the negative value of $\mathrm{K}_{\mathrm{L}} \mathrm{a}$ (Fig. 5). $\mathrm{K}_{\mathrm{L}} \mathrm{a}$ values obtained under laboratory conditions were converted to their equivalent values at $20^{\circ} \mathrm{C}$ and $101.3 \mathrm{kPa}$. Using the following equations:

$$
\begin{aligned}
& \mathrm{C}_{\mathrm{sp}}=\mathrm{C}_{\mathrm{LP}} \frac{\mathrm{P}_{\mathrm{ab}}}{\mathrm{P}_{\mathrm{at}}} \\
& \mathrm{K}_{\mathrm{L}} \mathrm{a}_{20}=\mathrm{K}_{\mathrm{L}} \mathrm{a}_{(\mathrm{T})}(1.24)^{20-\mathrm{T}}
\end{aligned}
$$

Where:

$\mathrm{C}_{\mathrm{Lp}}=$ The concentration of $\mathrm{O}_{2}$ in water at laboratory barometric pressure $\left(\mathrm{mgL}^{-1}\right)$

$\mathrm{C}_{\mathrm{sp}}=$ The concentration of $\mathrm{O}_{2}$ in water at standard atmospheric pressure $\left(\mathrm{mgL}^{-1}\right)$

$\mathrm{P}_{\mathrm{ab}}=$ The absolute laboratory barometric pressure $(\mathrm{kPa})$

$\mathrm{P}_{\mathrm{at}} \quad=$ The standard atmospheric pressure $(\mathrm{kPa})$

$\mathrm{K}_{\mathrm{L}} \mathrm{a}_{(20)}=$ The overall volumetric oxygen transfer coefficient at $20^{\circ} \mathrm{C}\left(\mathrm{min}^{-1}\right)$

$\mathrm{K}_{\mathrm{L}} \mathrm{a}_{(\mathrm{T})}=$ The overall volumetric oxygen transfer coefficient at atmospheric temperature ( $\mathrm{min}^{-}$ 1)

$\mathrm{T}=$ The water temperature $\left({ }^{\circ} \mathrm{C}\right)$

Equation 11 was used to correct the value of $\mathrm{C}_{\mathrm{s}}$ and equation 12 was used to correct the value of $\mathrm{K}_{\mathrm{L}} \mathrm{a}$. This left $\mathrm{K}_{\mathrm{L}}$ a exclusively a function of the design parameters of the disc aerator in the oxidation ditch.

\section{RESULTS}

Immersion depth experiments: The effect of immersion depth of $\mathrm{K}_{\mathrm{L}}$ a was studied at various levels of disc speed. The perforated disc of $0.64 \mathrm{~cm}$ thickness having 48 holes of $1.28 \mathrm{~cm}$ diameter and the nonperforated disc of the same thickness were used. The effect of the immersion depth on $\mathrm{K}_{\mathrm{L}}$ a at various disc speeds is shown in Fig. 6. The effect of the disc speed on $\mathrm{K}_{\mathrm{L}} \mathrm{a}$ at various immersion depths are shown in Fig. 7.

Hole diameter experiments: The results of these experiments are shown in Fig. 8-9. The effect of the hole diameter on $\mathrm{K}_{\mathrm{L}} \mathrm{a}$ at various disc speeds is sown in Fig. 8. The effect of the disc speed on $\mathrm{K}_{\mathrm{L}} \mathrm{a}$ at various hole diameters is shown in Fig. 9. 
Am. J. Applied Sci., 8 (7): 662-674, 2011
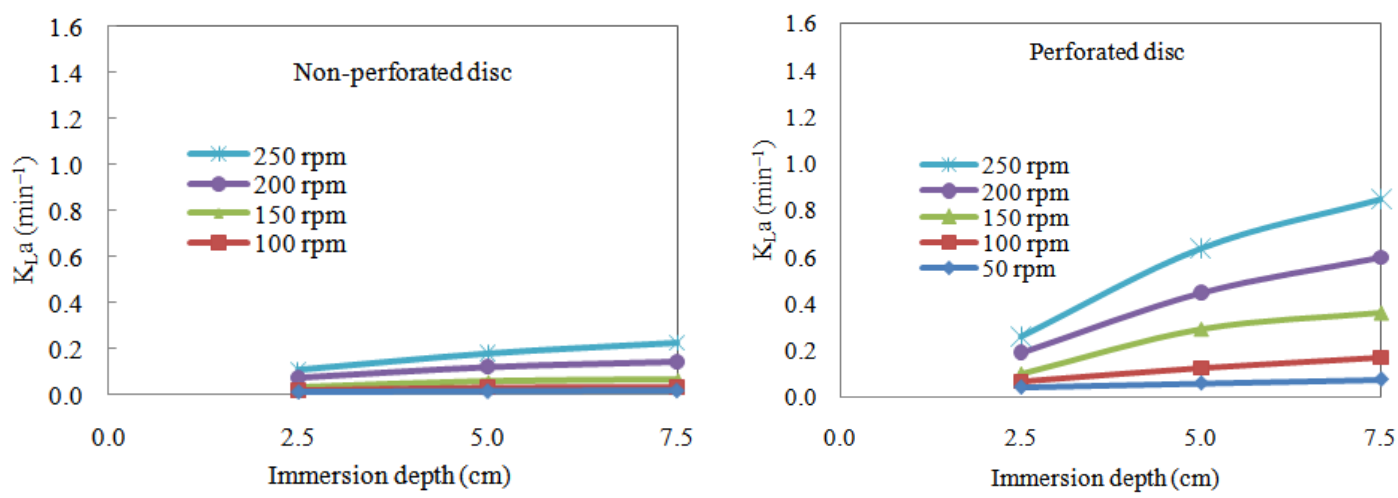

Fig. 6: Effects of immersion depth on $\mathrm{K}_{\mathrm{L}}$ a of $0.64 \mathrm{~cm}$ thick discs at various disc speeds
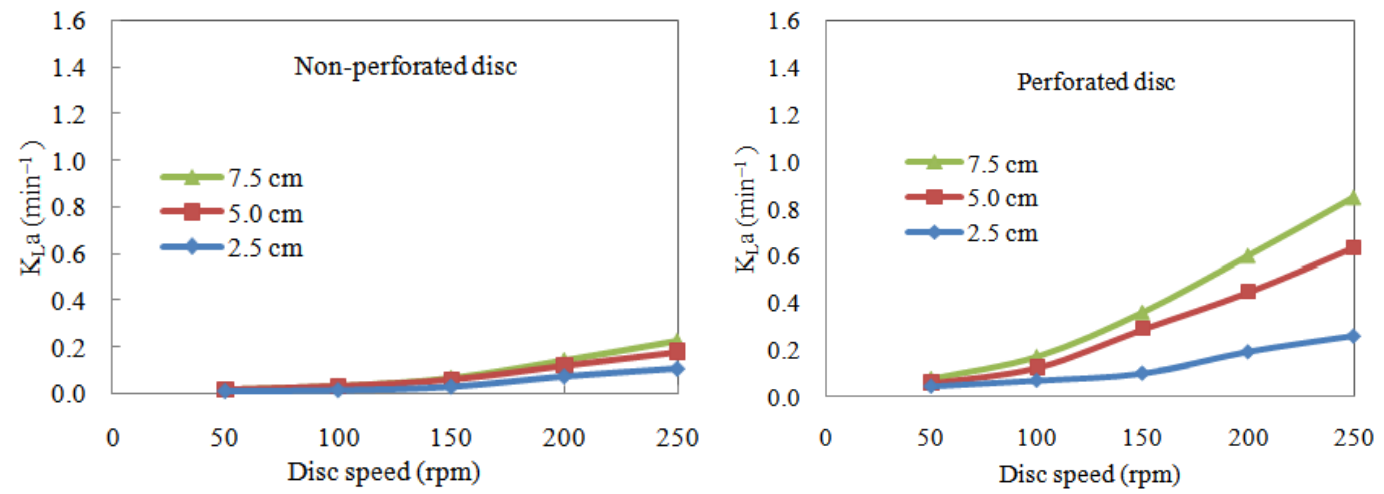

Fig. 7: Effects of disc speed on $\mathrm{K}_{\mathrm{L}}$ a of $0.64 \mathrm{~cm}$ thick discs at various immersion depths

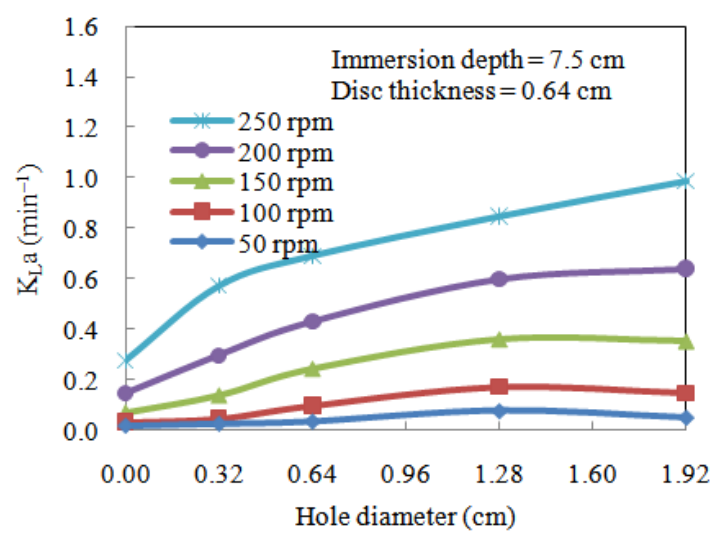

Fig. 8: Effect of hole diameter on the oxygen transfer coefficient at various disc speeds

Number of holes experiments: The results of these experiments are shown in Fig. 10-11. The effect of the number of holes per disc on $\mathrm{K}_{\mathrm{L}} \mathrm{a}$ at various disc speeds is shown in Fig. 10. The effect of disc speed on $\mathrm{K}_{\mathrm{L}}$ a at various numbers of holes is shown in Fig. 11.

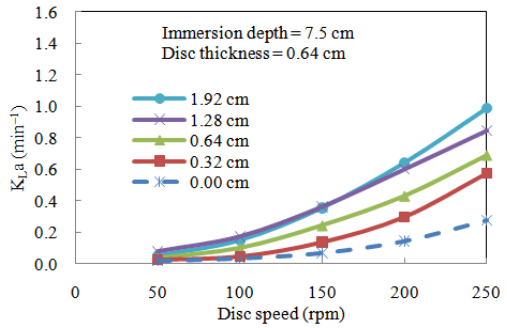

Fig. 9: Effect of disc speed on the oxygen transfer coefficient at various hole diameters

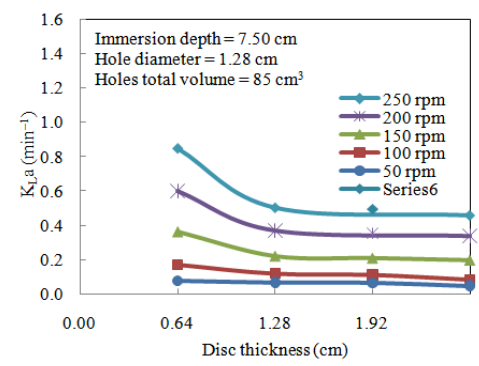

Fig. 10:Effect of number of holes on the oxygen transfer coefficient at various disc speeds 
Am. J. Applied Sci., 8 (7): 662-674, 2011

Table 1: $\mathrm{K}_{\mathrm{L}} \mathrm{a}$, oxygenation capacity, specific oxygenation capacity, power requirements and oxygenation efficiency of the aeration system

\begin{tabular}{|c|c|c|c|c|c|c|c|c|c|}
\hline \multirow[b]{3}{*}{ Speed (rpm) } & \multirow{3}{*}{$\begin{array}{l}\mathrm{K}_{\mathrm{L}} \mathrm{a} \\
\left(\mathrm{min}^{-1}\right)\end{array}$} & \multirow{3}{*}{$\begin{array}{l}\text { Oxygenation } \\
\text { capacity }\left(\mathrm{gO}_{2} / \mathrm{h}\right)\end{array}$} & \multirow{3}{*}{$\begin{array}{l}\text { Specific } \\
\text { oxygenation } \\
\text { capacity } \\
\left(\mathrm{gO}_{2} / \mathrm{h}\right)\end{array}$} & \multicolumn{4}{|c|}{ Power requirements } & \multirow{2}{*}{\multicolumn{2}{|c|}{$\begin{array}{l}\text { Oxygenation } \\
\text { efficiency }\left(\mathrm{gO}_{2} / \mathrm{MJ}\right)\end{array}$}} \\
\hline & & & & \multirow{2}{*}{$\begin{array}{l}\text { No load } \\
\text { (Watts) }\end{array}$} & \multirow{2}{*}{$\begin{array}{l}\text { load } \\
\text { (Watts) }\end{array}$} & \multicolumn{2}{|c|}{------------Net------- } & & \\
\hline & & & & & & (Watts) & $(\%)^{*}$ & Net & Gross \\
\hline 50 & 0.180 & 1.090 & 0.099 & 54 & 63 & 9 & 14 & 33.6 & 4.8 \\
\hline 100 & 0.366 & 2.220 & 0.202 & 61 & 72 & 11 & 15 & 56.1 & 8.6 \\
\hline 150 & 0.640 & 3.890 & 0.354 & 67 & 81 & 14 & 17 & 77.2 & 13.3 \\
\hline 200 & 0.916 & 5.560 & 0.505 & 74 & 90 & 16 & 18 & 95.7 & 17.2 \\
\hline 250 & 1.230 & 7.470 & 0.679 & 80 & 99 & 19 & 19 & 109.2 & 21.0 \\
\hline
\end{tabular}

*Percent of total power with load. Disc thickness $=2.55 \mathrm{~cm}$ Number of holes $=48$ Hole diameter $=1.92 \mathrm{~cm}$ Immersion depth $=7.5 \mathrm{~cm}$

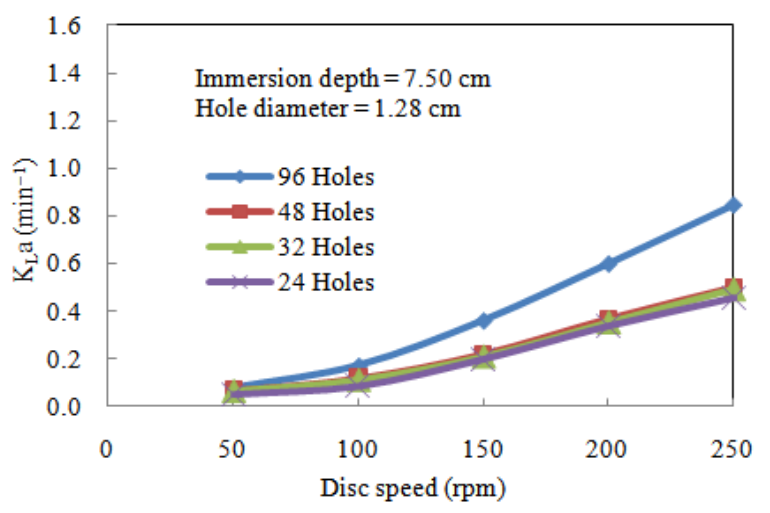

Fig. 11: Effect of disc speed on the oxygen transfer coefficient at various numbers of holes
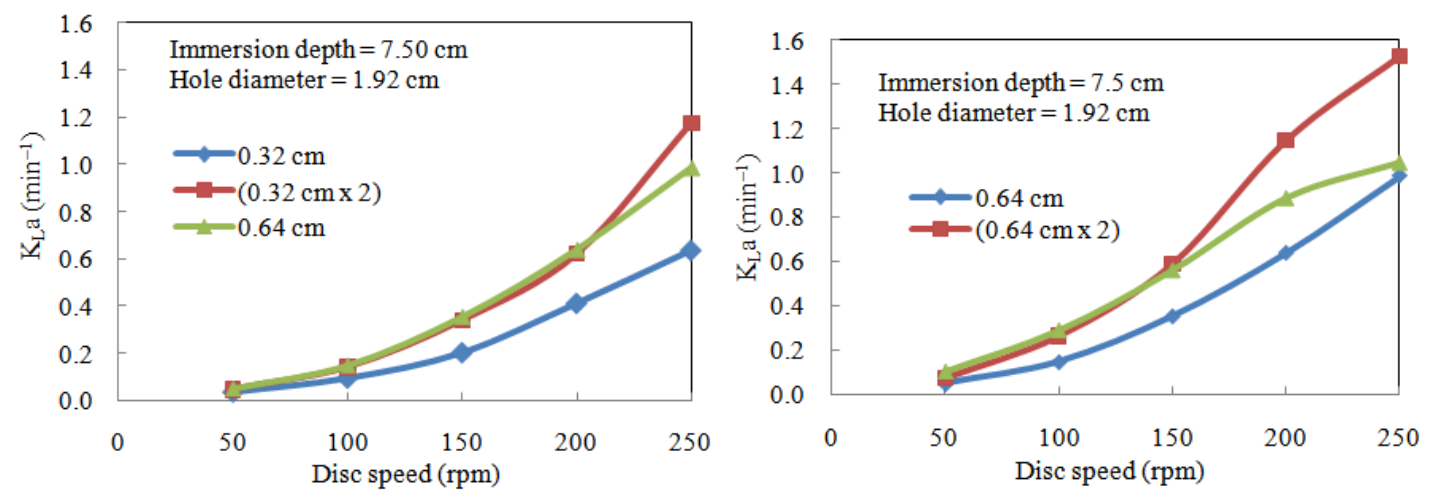

Fig. 12: Effect of disc speed on the oxygen transfer coefficient of single and double discs of various thicknesses

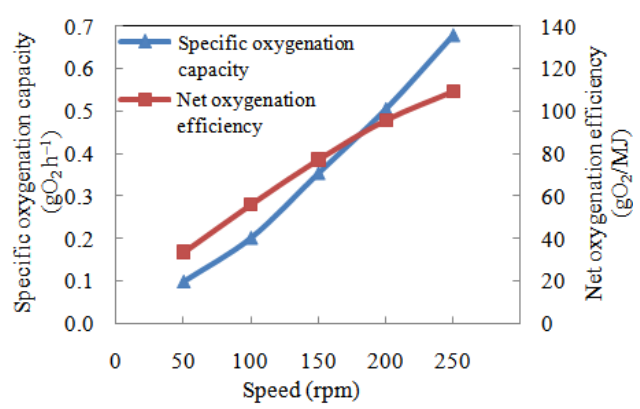

Fig.13: Oxygenation capacity and power requirements of the disc aerator in deionized water
Double disk experiments: The results of these experiments are shown in Fig. 12.

Oxygenation capacity: The $\mathrm{K}_{\mathrm{L}} \mathrm{a}$, input power, oxygenation capacity, specific oxygenation capacity and oxygenation efficiency are listed in Table 1. The oxygenation capacity and power requirements are also presented graphically in Fig. 13. The oxygenation capacity was calculated from $\mathrm{K}_{\mathrm{L}}$ a using Eq. 5. The specific oxygenation capacity was determined by dividing the oxygenation capacity by the ditch volume. The oxygenation efficiency was calculated by dividing the oxygenation capacity by the power consume. 
Am. J. Applied Sci., 8 (7): 662-674, 2011

\section{DISCUSSION}

Immersion depth: The immersion depth had a significant effect on $\mathrm{K}_{\mathrm{L}}$ a. Increasing the immersion depth increased $\mathrm{K}_{\mathrm{L}} \mathrm{a}$ for both the perforated and non-perforated discs. Increasing the immersion depth from $2.5-5.0 \mathrm{~cm}$ increased $\mathrm{K}_{\mathrm{L}}$ a by $30-93 \%$ for the non-perforated disc and by $40-193 \%$ for the perforated one, depending on the rotational speed. A further increase in immersion depth from $5.0-7.5 \mathrm{~cm}$ nearly doubled these values. This increase in $\mathrm{K}_{\mathrm{L}} \mathrm{a}$ was due to several factors. First, increasing the immersion depth increased the disc area passing through the liquid. About 32, 57 and $77 \%$ of the disc area were passing through the liquid for $2.5,5.0$ and $7.5 \mathrm{~cm}$ immersion depths, respectively (Table 3 ). Second, increasing the immersion depth increased the number of holes passing through the liquid (Fig. 14). For immersion depths of $2.5,5.0$ and $7.5 \mathrm{~cm}$ there were 38 , 70 and 96 holes passing through the liquid per revolution respectively. Third, increasing the immersion depth increased the average residence time of the holes and therefore, presumably the residence time of the bubbles. Fourth, increasing the immersion depth increased the extent of the oxygenated and thoroughly mixed layer (Table 4).

Table 2: Percentage increase in $\mathrm{K}_{\mathrm{L}}$ a due to increase in immersion depth, at various disc speeds

Increase in immersion depth

(from $2.5-5.0 \mathrm{~cm}$ ) (from $5.0-7.5 \mathrm{~cm}$ )

\begin{tabular}{llccl}
$\begin{array}{l}\text { Speed } \\
\text { (rpm) }\end{array}$ & $\begin{array}{l}\text { Non- } \\
\text { perforated }\end{array}$ & Perforated & $\begin{array}{l}\text { Non- } \\
\text { perforated }\end{array}$ & Perforated \\
\hline 50 & 30 & 40 & 56 & 77 \\
100 & 92 & 85 & 108 & 150 \\
150 & 93 & 193 & 120 & 264 \\
200 & 61 & 134 & 92 & 213 \\
250 & 67 & 147 & 111 & 229 \\
\hline
\end{tabular}

Table 3: The effect of immersion depth on the disc area passing through the liquid, the number of holes per revolution and the thickness of the oxygenated layer

\begin{tabular}{lllll}
\hline $\begin{array}{l}\text { Immersion } \\
\text { depth } \\
(\mathrm{cm})\end{array}$ & $\begin{array}{l}\text { Disc area } \\
\text { passing } \\
\text { through } \\
\text { Liquid }\left(\mathrm{cm}^{2}\right)\end{array}$ & $\begin{array}{l}\text { Number } \\
\text { of holes } \\
\text { per } \\
\text { revolution }\end{array}$ & $\begin{array}{l}\text { Oxygenated } \\
\text { layer } \\
(\%)\end{array}$ \\
\hline 2.5 & 208 & 32 & 38 & 23 \\
5.0 & 377 & 57 & 70 & 46 \\
7.5 & 506 & 77 & 96 & 69 \\
\hline
\end{tabular}

Table 4: Percentage increase in $\mathrm{K}_{\mathrm{L}} \mathrm{a}$ due to the presence of holes, at various immersion depths and disc speeds.

\begin{tabular}{llll}
\hline & \multicolumn{1}{l}{ Immersion depth (cm) } & \\
Speed (rpm) & $-{ }^{2.5}$ & 5.0 & 7.5 \\
\hline 50 & 272 & 304 & 323 \\
100 & 335 & 320 & 424 \\
150 & 219 & 383 & 317 \\
200 & 157 & 271 & 272 \\
250 & 140 & 254 & \\
\hline
\end{tabular}

Cancino (2004) found that $\mathrm{K}_{\mathrm{L}}$ a increased as depth increased for a flat plate aerator up to an immersion depth of $235 \%$ of paddle height. Moulick et al. (2002) found the immersion depth of a paddle wheel aerator to have a significant effect on aeration. Al-Ahmady (2006) investigated the oxygen transfer capacity in a bench scale subsurface aerator and found that by increasing the water depth the average bubble residence time increased allowing more time for oxygen transfer to occur. As water depth rose from 0.5-4.6 m $(820 \%$ increase) the oxygen transfer capacity rose from 18-170 $\mathrm{gO}_{2} / \mathrm{m}^{3} \mathrm{hr}$ (844\% increase). Gillot et al. (2005) and Bayramoglu et al. (2000) developed models to determine oxygen transfer rates in diffused air aeration tanks and found the water depth to have significant effect on the oxygen transfer.

In this experiment the effect of disc speed on the $\mathrm{K}_{\mathrm{L}} \mathrm{a}$ was also extensive. Increasing the disc speed increased $\mathrm{K}_{\mathrm{L}} \mathrm{a}$ for both the perforated and nonperforated discs. The rate of increase was dependent on the immersion depth; the greater the depth the more rapid was the increase in $\mathrm{K}_{\mathrm{L}} \mathrm{a}$. For all disc speeds however, the perforated disc had much higher $\mathrm{K}_{\mathrm{L}} \mathrm{a}$ values compared to those of the non-perforated disc. Increasing the number of holes increased the number of bubbles passing through the liquid per unit time, although it decreased the average residence time.

Paolini (1986) performed a study on a Rotating Biological Contractor (RBC) aerator used in waste water treatment and found that as the disc speed increased from $3 \mathrm{rpm}$ to $25 \mathrm{rpm}\left(733 \%\right.$ increase), $\mathrm{K}_{\mathrm{L}} \mathrm{a}$ increased from $0.11-0.33 \mathrm{~min}^{-1}$ (200\% increase). Moulick et al. (2002) obtained similar results when adjusting mixing speed in a paddle wheel aerator. Clarke et al. (2006) tested the effects of alkalinity on the oxygen transfer coefficient in a New Brunswick bioreactor and found that the effects of alkalinity were tied to the speed of the impeller. The addition of alkalinity increased $\mathrm{K}_{\mathrm{L}} \mathrm{a}$ at speeds above $300 \mathrm{rpm}$ and reduced $\mathrm{K}_{\mathrm{L}}$ a at speeds below $300 \mathrm{rpm}$. The authors concluded that alkalinity improved turbulence and thus oxygen transfer rate.

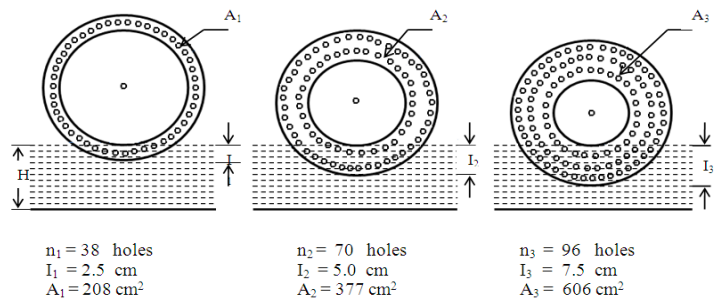

Fig. 14: The effect of the immersion depth on the disc wet area and the number of holes passing through the liquid per revolution 
Am. J. Applied Sci., 8 (7): 662-674, 2011

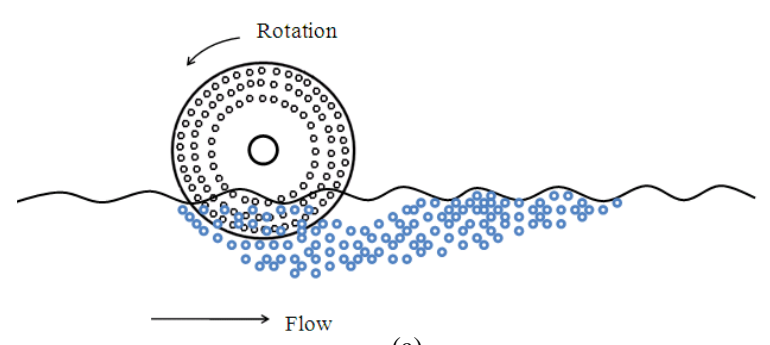

(a)

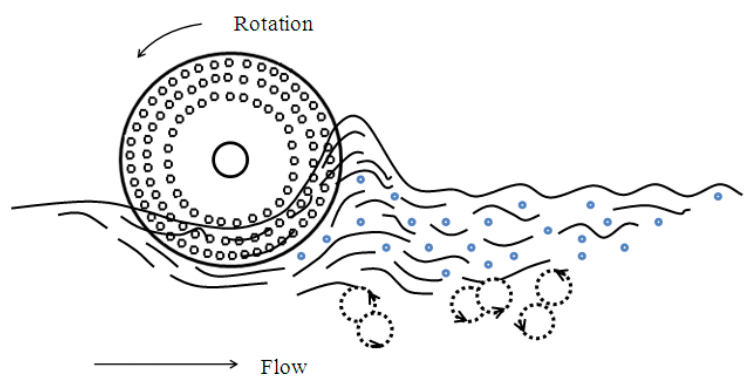

(b)

Fig. 15:Path of bubbles and formation of eddies by disc aerator. (a) Path of air bubbles at low speed (50 rpm). (b) Formation of bubbles and eddies at high speed (250 rpm)

Effect of hole diameter: The presence of holes as well as the diameter of these had a great effect on $\mathrm{K}_{\mathrm{L}} \mathrm{a}$. The presence of small holes of $0.32 \mathrm{~cm}$ diameter increased the $\mathrm{K}_{\mathrm{L}} \mathrm{a}$ value by $44-152$ percent over that of the nonperforated disc, depending on the rotational speed. A further increase in the hole diameter from $0.32-1.92 \mathrm{~cm}$ resulted in additional increases in $\mathrm{K}_{\mathrm{L}} \mathrm{a}$ of 134-182 percent. There were only slight differences amongst $\mathrm{K}_{\mathrm{L}} \mathrm{a}$ values obtained for discs having holes of 1.28 and $1.92 \mathrm{~cm}$ diameter.

Disc speed also extensively affected $\mathrm{K}_{\mathrm{L}} \mathrm{a}$. Increasing the disc sped increased $\mathrm{K}_{\mathrm{L}}$ a rapidly for both perforated and non-perforated discs. Increasing the disc speed from 50 to $250 \mathrm{rpm}$ increased the $\mathrm{K}_{\mathrm{L}}$ a value by 1161 percent for the non-perforated disc and by 1872 to 2100 percent for the perforated discs, depending on the hole diameter.

Effect of number of holes: In this experiment the two factors, disc thickness and number of holes per disc, were confounded (i.e. the two factors were not cross classified; all levels of each factor did not appear with each level of the other) since the perforated volume of each disc was the same. The effects of these two factors could therefore not be separated. The experiment was arranged in this manner so that for all discs, at equal rotational speed, equal quantities of air (in the holes) would be transferred below the liquid surface.
In this experiment the effect of the disc speed on $\mathrm{K}_{\mathrm{L}} \mathrm{a}$ was profound. For all discs, increasing the disc speed increased $\mathrm{K}_{\mathrm{L}}$ a rapidly. Increasing the disc speed from 50-250 rpm increased the $\mathrm{K}_{\mathrm{L}}$ a value by $829-1014$ percent depending on the number of holes.

It should be noted that, except for the disc which had a $0.64 \mathrm{~cm}$ thickness ( 96 holes), the $\mathrm{K}_{\mathrm{L}}$ a achieved at a given rotational speed was relatively constant, irrespective of the disc thickness (and number of holes). These observations were interpreted as being due to two opposing effects: an increase in $\mathrm{K}_{\mathrm{L}}$ a due to an increase in the number of holes and a simultaneous decrease in $\mathrm{K}_{\mathrm{L}} \mathrm{a}$ due to a decrease in disc thickness. Apparently, for most of the discs theses two effects practically cancelled each other.

Double disc: For all aerator discs (single and double), increasing the disc speed increased the $\mathrm{K}_{\mathrm{L}}$ a rapidly. Increasing the disc speed from 50-250 rpm increased $\mathrm{K}_{\mathrm{L}}$ a by $583-1824$ percent for single aerator discs and by 1990-2456 percent for double aerator discs, depending on the disc thickness.

It should be noted that $\mathrm{K}_{\mathrm{L}}$ a values obtained from a double aerator disc of $0.32 \mathrm{~cm}$ thickness (two discs of $0.32 \mathrm{~cm}$ thickness each, spaced at $2.5 \mathrm{~cm}$ and operating in parallel) were similar to those obtained with the single disc of $0.64 \mathrm{~cm}$ thickness over most of the speed range; it was however 19 percent greater at $250 \mathrm{rpm}$. For the double aerator disc of $0.64 \mathrm{~cm}$ thickness, at lower speeds (50-150 rpm) $\mathrm{K}_{\mathrm{L}}$ a values were lower than those of single discs of $1.28 \mathrm{~cm}$ thickness. At higher speeds, they were however considerably greater; up to 46 percent at $250 \mathrm{rpm}$.

Visual observations: High speed movies were taken during an aeration test in order to gain a better understanding of the physical processes involved in the oxygen transfer. The films were analyzed frame-byframe on a photo optical data analyzer which gave a good picture of the liquid and air bubble movement. Three mechanisms are believed to have contributed simultaneously to the process of oxygen transfer. They are (a) bubble aeration, (b) eddy aeration and (c) surface aeration.

The holes of the disc had a great effect on the addition of bubbles and creation of turbulence in the liquid. The bubbles are formed when the disc enters the liquid and the latter replaces the air trapped in the holes. The bubbles are then detached from the disc and continue with the fluid as shown in Fig. 15. The oxygen transfer then occurs from the air bubbles into the liquid phase through the gas-liquid interface. 
The disc not only adds bubbles to the liquid but also serves as an agitator. The liquid is caught by the edges of the holes and eddies are formed. As the disc rotates and holes leave the liquid, a mass of eddies is brought above the surface of the liquid as shown in Fig. 15 . These eddies are considered as continually exposing fresh liquid surface to the air, then gliding swiftly away and mixing into the bulk of liquid. During the exposure of any portion of the liquid to air, transfer of oxygen occurs by molecular diffusion as described previously. The rate of production of fresh surface is a function of the disc rotational speed. Deglon et al. (1998) stated that intermediate and high frequency eddies are better able to cause bubble breakup. They found that spinning non-perforated discs tend to generate low frequency eddies and recommend the addition of grooves or cuts to the edges of the discs to improve bubble breakup. In this study, the larger hole diameter and higher speed created high frequency eddies with improved bubble breakup and higher oxygen transfer.

Oxygen transfer, from atmosphere to the liquid body, may also take place at the liquid surface in the ditch. The dissolved oxygen concentration of the surface layer will be higher than that of the bottom layer so that the oxygen will be transferred downwards. Eckenfelder (1959) found that surface aeration is the result of bubble breakup and the velocity gradients present at the liquid air interface. Ghaly and Edwards (2011) found that increasing the disc speed increased the water velocity at the surface layer and improved the oxygen transfer rate.

Oxygenation capacity: The oxygenation capacity of the system was a function of $\mathrm{K}_{\mathrm{L}} \mathrm{a}$ and was thus affected by the immersion depth, hole diameter, disc thickness and disc speed with the disc speed having the greatest effect. Increasing the disc speed from 50-250 rpm ( $400 \%$ increase) increased the oxygenation capacity by $585 \%$.

Thakre et al. (2008) assessed the effects of immersion depth on the oxygenation capacity and power consumption of paddle wheel aerators and found that increasing immersion depth allowed for a marginal increase in oxygenation capacity and a dramatic rise in power consumption. Thakre et al. (2009) tested the effects of immersion depth on the oxygenation capacity of curved blade aerators and found that as immersion depth was increased from 4.8-7.2 $\mathrm{cm}$ (50\% increase), the oxygen transfer coefficient $\left(\mathrm{K}_{\mathrm{L}} \mathrm{a}\right)$ rose from 8.41$10.93 \mathrm{~h}^{-1}$ (30\% increase) and the power consumption almost doubled (from 69.9-136.0 W). Pasveer (1953) investigated the effect of immersion depth of a $42 \mathrm{~cm}$ diameter brush aerator on the oxygenation capacity and found that when the immersion depth was increased from $5-14 \mathrm{~cm}$ (180\% increase), the oxygenation capacity rose from $147-391 \mathrm{~g} / \mathrm{hr} \mathrm{m}^{3}$ (166\% increase).

Although the measurement of the power consumption of a model scale system is not necessarily meaningful, it was done for the sake of completeness. The results showed that the drive system of the aerator disc was rather inefficient; only about $14-19 \%$ of the input power was apparently consumed in the aeration process. This would not necessarily be the cause in a full-scale ditch in which an efficient aerator disc drive system would be installed. However, increasing the disc speed from 50-250 rpm (400\% increase) increased the net power by $110 \%$ and the net oxygenation efficiency by $225 \%$.

As is evident from the results, the system studied achieved a very high specific oxygenation capacity. However, as the specific oxygenation capacity of a system is increased, the allowable maximum oxygen demand of the medium can be increased to allow more concentrated waste to be treated. . This then may result in a smaller ditch volume but higher energy requirements. Therefore, in the design of an aeration system these two evaluation factors may be traded off against each other to find the highest specific oxygenation capacity at the lowest total cost.

\section{CONCLUSION}

The use of sodium sulphite with cobalt chloride for deoxygenation of the water via the oxidation ditch was effective and the results were very consistent and repeatable. The oxygen transfer coefficient was affected by the immersion depth, hole diameter, disc speed, disc thickness and number of discs with the disc speed having the greatest effect. The results showed that three physical processes simultaneously contributed to oxygen transfer by the disc aerator: bubble aeration, eddy aeration and surface aeration. The aerator disc of $2.55 \mathrm{~cm}$ thickness, $1.92 \mathrm{~cm}$ diameter and 48 holes was found to be achieved the highest oxygenation capacity. The system is anticipated to provide a broad range of oxygen transfer rates under actual conditions (23-164 $\mathrm{mgO}_{2} / \mathrm{L}-\mathrm{h}$ ) to meet varying process demands encountered in aerobic treatment systems. However, increasing the specific oxygenation capacity will increase the power requirement and these two factors may be traded off against each other to find the most effective oxygenation capacity with the lowest total cost.

\section{ACKNOWLEDGEMENT}

This research was supported by the National Science and Engineering Research Council (NSERC) of Canada. 


\section{REFERENCES}

Al-Ahmady, K.K., 2006. Analysis of oxygen transfer performance on sub-surface aeration systems. Int. J. Environ. Res. Public Health, 3: 301-308. DOI: 10.1016/S0144-8609(01)00087-5

Bayramoglu, M., A., Cakici and T., Tekin, 2000. Modelling of Oxygen transfer rate in diffused-air aeration tanks. Process Safety Environ. Protection. 78: 209-212. DOI: 10.1205/095758200530655

Cancino, B., 2004. Design of high efficiency surface aerators: Part 2. Rating of surface aerator rotors. Aquac. Eng., 31: 99-115. DOI: 10.1016/j.aquaeng.2004.03.003

Clarke, K.G., P.C. Williams, M.S. Smit and S.T.L. Harison, 2006. Enhancement and repression of the volumetric oxygen transfer coefficient through hydrocarbon addition and its influence on oxygen transfer rate in stirred tank bioreactors. Biochem. Eng. J., 28: 237-242. DOI: 10.1016/j.bej.2005.11.007

Dankwarts, P.V., 1951. Significance of liquid film coefficient in gas absorption. Indus. Eng. Chem., 43: 1460-1467.

Deglon, D.A., C.T. O'Connor and A.B. Pandit, 1998. Efficacy of a spinning disc as a bubble break-up device. Chem. Eng. Sci., 53: 59-70. DOI: 10.1016/S0009-2509(97)00309-6

Drews, R.J.L.C., W.M. Malan, P.G.J. Meiring and B. Moffatt, 1972. The orbal extended aeration activated sludge plant. Water Pollution Control Federation, 44: 221-231. http://www.jstor.org/pss/25037300

Eckenfelder, W.W., 1959. Factors affecting the aeration efficiency of sewage and industrial wastes. Sewage Indus. $\quad$ Wastes, 31: 60-70. http://www.jstor.org/pss/25033795

Fenlon, D.R. and P.J., Mills, 1980. On farm aerobic treatment of piggery waste. The effect of residence time and storage on effluent quality. Water Res., 14: 805-808. DOI: $10.1016 / 0043-1354(80) 90260-2$

Ghaini, A., M.N. Kashid and D.W. Agar, 2010. Effective interfacial area for mass transfer in the liquid-liquid slug flow capillary microreaSctors. Chem. Eng. Process., Process Intensification. 49: 358-366. DOI: 10.1016/J.CEP.2010.03.009

Ghaly, A.E. and R. Kok, 1986. Nitrogen transformation in swine manure in an oxidation ditch under anaerobic conditions. Trans. Am. Soc. Agric. Eng., 29: 799-806. http://asae.frymulti.com/abstract.asp?aid=30232\&t $=1$
Ghaly, A.E. and R. Kok, 1988. The effect of sodium sulphite and cobalt chloride on the oxygen transfer coefficient. Applied J. Biochem. Biotechnol., 19: 259-270. DOI: 10.1007/BF02921498

Ghaly, A.E. and S. Edwards, 2011. Factors affecting the oxygenation capacity of a disc aerator in an oxidation ditch system. American J. Environ. Sci., 7: 108-118. DOI: 10.3844/ajessp.2011.108.118

Gillot, S., S. Capela-Marsal, M. Roustan and A. Heduit, 2005. Predicting oxygen transfer of fine bubble diffused aeration systems-model issued from dimensional analysis. Water Res., 39: 1379-1387. DOI: 10.1016/j.watres.2005.01.008

Gomolka, E. and B. Gomolka, 1991. Application of dick aerators to recarbonation of alkaline wastewater from wet gasification of carbide. Water Sci. Technol., 24: 277-284. http://md1.csa.com/partners/viewrecord.php?reque ster $=$ gs\&collection $=$ TRD\&recid $=20070430137427$ $\mathrm{CE}$

Gresch, M., M. Armbruster, D. Braun and W. Gujer, 2010. Effects of aeration patterns on the flow field in wastewater aeration tanks. Water Res., 45: 810818. DOI: 10.1016/j.watres.2010.09.009

Groves, K.P., G.T. Daigger, T.J. Simpkin, D.T. Redmon and L. Ewing, 1992. Evaluation of oxygen transfer efficiency and alpha-factor on a variety of diffused aeration systems. Water Environ. Res., 64: 691-698. http://www.jstor.org/stable/25044209.

Haut, B. and V., Halloin, 2003. Mass transfer in gasliquid contactors: a new technique for numerical solution of the film equations. Chem. Eng. Processing: Gas-Liquid Gas-Liquid-Solid Reactor Eng., $\quad 43$ : $1339-1346 . \quad$ DOI: 10.1016/j.cep.2003.07.002

Jones, D.D., D.L. Day and A.C. Dale, 1971. Aerobic treatment of livestock waste. bulletin no. 737, agricultural experiment station of Illinois at Urbana, Champaign, 1c. http://www.ideals.illinois.edu/bitstream/handle/214 2/8594/aerobictreatment00jone.pdf?sequence $=1$

LaPara, T.M. and J.E. Alleman, 1998. Thermophilic Aerobic Biological Wastewater Treatment. Water Res., 33: 895-908. DOI: $\quad 10.1016 /$ S00431354(98)00282-6

Liu, Y., H. Shi, L. Xia, H. Shi and T. Shen et al., 2009. Study of operational conditions of simultaneous nitrification and denitrification in a Carrousel oxidation ditch for domestic wastewater treatment. Bioresource Technol., 101: 901-906. DOI: 10.1016/j.biortech.2009.09.015 
McCabe, W., J. Smith and P. Harriott, 2004. Unit Operation of Chemical Engineering, 7th Edn., McGraw-Hill Book Company, New York, ISBN10: 0072848235, pp: 1152.

Miller, D.N., 1964. Liquid film control and mass transfer in agitated vessels. Indus. Eng. Chem., 56: 18-27. DOI: 10.1021/ie50658a004

Moulick, S., B.C. Mal and S. Bandyopadhyay, 2002. Prediction of aeration performance of paddle wheel aerators. Aquacultural Eng., 25: 217-237. DOI: 10.1016/S0144-8609(01)00087-5

Nedeltchev, S., U., Jordan and A., Schump, 2007. Correction of the penetration theory based on mass-transfer data from bubble columns operated in the homogeneous regime under high pressure. Chem. Eng. Sci., 62: 6263-6273. DOI: 10.1016/j.ces.2007.07.030

Paolini, A.E., 1986. Effect of biomass on oxygen transfer in RBC systems. Water Pollut. Control Federation, 58: 306-311. http://www.jstor.org/pss/25042906

Pasveer, A., 1953. Reserach on activated sludge: II. Experiments with brush aeration. Sewage Indus. Wastes, 25: 1397-1404. http://www.jstor.org/pss/25032354

Pawar, N.A., J.K. Jena, P.C. Das and D.D. Bhatnagar, 2009. Influence of duration of aeration on growth and survival of carp fingerlings during high density seed rearing. Aquaculture, 290: 263-268. DOI: 10.1016/j.aquaculture.2009.02.030
Pell, M. and A. Worman, 2008. Biological wastewater treatment systems, Encyclopedia Ecology. Elsevier, B.V., Stockholm, Sweden. DOI: 10.1016/B978-008045405-4.00317-7

Thakre, S.B., L.B. Bhuyar and S.J. Deshmukh, 2008. Effect of different configurations of mechanical aerators on oxygen transfer and aeration efficiency with respect to power consumption. Int. J. Mechanical, Indus. Aerospace Eng., 2: 100-108. www.waset.org/journals/ijame/v2/v2-2-15.pdf

Thakre, S.B., L.B. Bhuyar and S.J. Deshmukh, 2009. Oxidation ditch process using curved blade rotor as aerator. Int. J. Environ. Sci. Technol., 6: 113-112. http://www.emro.who.int/imemrf/ijes_2009_6_1_1 13.pdf

Wang, J., 1995. Flow reactor models for fluid-fluid systems, based on the two-film theory. Chem. Eng. J. Biochem. Eng. J., 60: 105-110. DOI: 10.1016/0923-0467(95)03003-4

Wu, H., 1995. An issue on applications of a disk turbine for gas-liquid mass transfer. Chem. Eng. Sci., 50: 2801-2811. DOI: 10.1016/0009-2509(95)00122-L

Xia, S. and J., Liu, 2003. An innovative integrated oxidation ditch with vertical circle for domestic wastewater treatment. Process Biochem.. 39: 11111117. DOI: 10.1016/S0032-9592(03)00216-4

Xie, B., X.-C. Dai and Y.-T. Xu, 2006. Cause and prealarm control of bulking and foaming by Microthrix parvicella-A case study in triple oxidation ditch at a wastewater treatment plant. J. Hazardous Materials. 143: 184-191. DOI: 10.1016/j.jhazmat.2006.09.006 